\title{
ARTES VISUALES EN CHILE DURANTE LA PRIMERA MITAD DEL SIGLO XX: UNA MIRADA AL CAMPO TEÓRICO ${ }^{1}$
}

\author{
VISUAL ARTS IN CHILE DURING THE FIRST HALF OF \\ THE XX CENTURY: A LOOK AT THE THEORETICAL FIELD
}

\section{PEDRO EMILIO ZAMORANO²}

\section{RESUMEN}

El trabajo analiza el escenario de la crítica de arte en el país, desde las últimas décadas del siglo XIX hasta la mitad de la pasada centuria. Revisa las voces y discursos iniciales, estableciendo sus modelos, estilos y formas de expresión y difusión. Profundiza en algunos autores tales como Ricardo Richon-Brunet, Antonio Romera y Jean Emar, vinculando sus discursos teóricos con aquellos momentos y contenidos más importantes del arte nacional. Analiza también la gravitación que tuvieron algunas exposiciones de arte realizadas en Chile, concluyendo con una revisión a la historiografía de la escultura en el país.

Palabras clave: Crítica, pintura, escultura, Chile, artistas, modelos.

\section{ABSTRACT}

This work analyses the scene of critics of Art in the country from the last decades of the XIX century up through the last half of the XX century. It reviews the voices and initial speeches, establishing models, styles and forms of expression and diffusion. It goes deeper into some authors such as Ricardo Richon-Brunet, Antonio Romera y Jean Emar, relating their theoretical speeches with the most important moments and con-

${ }^{1}$ El presente artículo corresponde al Proyecto de Investigación "Escultura chilena 1854-1960: el trasluz de su identidad”, Fondecyt No 1085295, dirigido por el autor de este trabajo e integrado por el académico Claudio Cortés López, coinvestigador; el escultor Francisco Gazitúa, coinvestigador, y las historiadoras Marisol Richter y Cynthia Valdivieso.

${ }^{2}$ Dr. en Historia del Arte, Profesor Titular Instituto de Estudios Humanísticos Abate Juan Ignacio Molina, Universidad de Talca. Talca, Chile. E-mail: pzamoper@utalca.cl 
tents of national art. It also analyses the importance that some of the art expositions had in the country, concluding with a revision of the local sculpture historiography.

Keywords: Critics, painting, sculpture, Chile, artists, models.

\section{ANTECEDENTES}

XISTEN dos momentos claramente diferenciados en el panorama de la crítica de arte en Chile durante las primeras cinco décadas del siglo XX: el primero, que calificaremos como de orientación e información inicial, a través de crónicas escritas, entre otros, por Ricardo Richon Brunet, Nathanael Yáñez Silva, más algunas figuras provenientes del ámbito literario. Otro, de conformación del gusto o esclarecimiento de los movimientos vanguardistas, en figuras como Jean Emar y Antonio Romera, personalidades que se encargaron de instruir a un público masivo, diletante y con poca información sobre procesos estéticos. La labor crítica de estos autores consistió en alfabetizar al público nacional en torno al desarrollo universal del arte, especialmente las corrientes más vanguardistas.

Distinguimos también un tercer momento, materia de otro trabajo, que dice relación con la aparición de un conjunto de críticos, entre ellos Luis Oyarzún, Jorge Elliot y Enrique Lihn, que legitiman sus proyectos de escritura desde el campo académico. La actividad de estos teóricos se proyecta hasta la década de los setenta.

\section{VOCES Y DISCURSOS INICIALES}

El desarrollo de las artes visuales en Chile ha tenido por característica una cierta orfandad de sustento teórico. Del quehacer de nuestros artistas han quedado sus pinturas o esculturas, y una escasa información sobre aspectos relacionados con la historia, la teoría o la crítica. Durante la segunda mitad del siglo XIX encontramos ya algunas crónicas, ensayos y textos que nos ilustran acerca de la sensibilidad y conceptos estéticos de la época. Entre ellos, el discurso de Alejandro Cicarelli, leído con motivo de la inauguración de la Academia de Pintura en 1849, también algunos textos de José Miguel Blanco, Pedro Francisco Lira Recabarren, Paulino Alfonso, Ignacio Domeyko, Emilio Rodríguez Mendoza, Arturo Blanco, Vicente Grez y Virginio Arias, entre otros ${ }^{3}$.

\footnotetext{
${ }^{3}$ Escritos de estos autores figuran en Anales de Artes Plásticas de la Universidad de Chile, re-
} 
En los años iniciales del siglo XX la contribución teórica más importante fue el Diccionario biográfico de pintores 4 , de Pedro Lira (1902). Luego van adquiriendo protagonismo otras voces, entre ellas las de Ricardo RichonBrunet ${ }^{5}$ y Nathanael Yáñez Silva ${ }^{6}$, además de varios aportes procedentes del ámbito literario, entre ellos Manuel Magallanes Moure ${ }^{7}$, Pedro Prado ${ }^{8}$, Álvaro Yáñez Bianchi (Jean Emar) ${ }^{9}$, Augusto D’Halmar ${ }^{10}$, Vicente Huidobro y, ya hacia el ecuador del siglo, el español Antonio Romera. A estos nombres debemos sumar la figura del maestro Juan Francisco González. Estos intelectuales, sin lugar a dudas, contribuyeron a la formación de una cierta cultura estético-visual en el país, mas no lograron dar forma a una crítica profesionalizada, o a configurar una tradición historiográfica demasiado profunda en el ámbito de las artes visuales en el país. Hay todavía mucha información referida a movimientos, escuelas, monografías, catalogaciones y otros antecedentes importantes, que están a la espera de un examen teórico, de una publicación o, al menos, de su registro documental.

copilación de Rosario Letelier, Emilio Morales y Ernesto Muñoz, publicado por el Museo de Arte Contemporáneo de esa Universidad, en 1993.

${ }^{4}$ Lira escribió, además, desde 1866 sobre arte en los Anales de la Universidad de Chile, en la Revista de Santiago y en el Correo Literario.

${ }^{5}$ Ricardo Richon-Brunet (1866-1946), pintor y crítico de arte francés, llegado a Chile en 1900. En 1910 fue designado como Comisario General de la Exposición del Centenario, oportunidad en que escribió el catálogo oficial de la exposición.

${ }^{6}$ Nathanael Yáñez Silva (1884-1965). Periodista, dramaturgo y crítico teatral. Obtuvo el Premio Nacional de Teatro en 1953. Se dedica también a la crítica pictórica, la que enfrenta desde una mirada tradicional, adhiriendo a los principios neoclasicistas. En la revista Zig-Zag publicó crónicas de arte, bajo el título de "Actualidad artística", "Horas de taller" y "Visiones artísticas". En sus crónicas "Interiores" habla de las principales colecciones artísticas de las familias santiaguinas.

${ }^{7}$ Manuel Magallanes Moure (1878-1924). Poeta, cuentista, pintor y dramaturgo. Realizaba crítica literaria, crónica, comentarios pictóricos y reportajes. Junto a Pedro Prado y otros integra el Grupo Los Diez y también la Colonia Tolstoyana. En la revistas Zig-Zag, Pacífico Magazine y Selecta, entre otras, escribió sobre pintura chilena, escultura, artistas, etc.

${ }^{8}$ Pedro Prado (1886-1952). Poeta, novelista y cuentista. En 1949 recibió el Premio Nacional de Literatura. Escribió artículos de arte en la revista Arte y Cultura, en Zig-Zag, la revista Juventud, entre otras.

${ }^{9}$ Álvaro Yáñez Bianchi (1893-1964), más conocido como Jean Emar. Novelista, crítico, pintor y viajero. Escribió sus crónicas de arte en el diario La Nación. Fue un entusiasta impulsor en Chile de las vanguardias artísticas europeas, especialmente aquellas que estaban en el patrón genético de los artistas vinculados al Grupo Montparnasse.

${ }^{10}$ Augusto D’Halmar (1882-1950). Escritor y diplomático, en 1900 fue nombrado redactor de la revista Luz y Sombra. Junto a Fernando Santiván y el pintor Julio Ortiz de Zárate fundó en 1904 la Colonia Tolstoyana, convocando en ella a algunos pintores y escultores de la época.

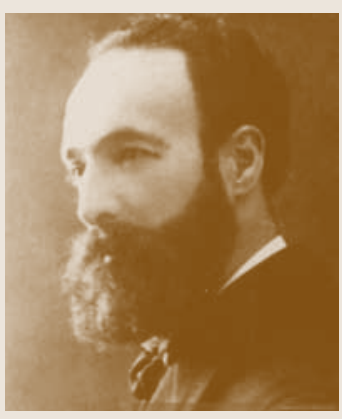

M. Magallanes

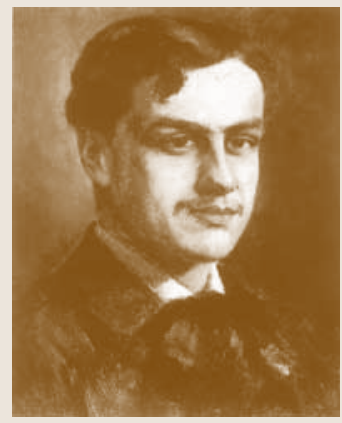

A. D’Halmar

(retrato de J. F. González) 


\section{CAMPO TEÓRICO: FORMALIDADES Y CIRCULACIÓN}

$\mathrm{Al}$ analizar la primera mitad del siglo XX nos encontramos con una producción, más heterogénea que abundante, de textos que glosan la escena estética local. Es posible distinguir aquí dos tipos de escritos. Uno, a nivel de crónicas y artículos breves, que relevan un tipo de información monográfica y documental. Estos trabajos ilustran sobre distintos aspectos del quehacer estético local: autores, exposiciones, biografías, obras, entre otros. Varios fueron los autores y los medios a través de los cuales se difundieron estos escritos que, en lo formal, se relacionan con un tipo de información más genérica e informativa, muy confiada a "impresiones" y a la sensibilidad de la pluma de sus autores. El soporte más frecuente de estos escritos fue la prensa escrita. Este tipo de información adquirió en nuestro país una gran significación, pues pasó a ser el orientador, casi exclusivo, de la opinión pública en este ámbito. La breve extensión de un artículo y su necesidad de informar sobre temas contingentes a un público masivo y heterogéneo hacen que el texto quede liberado a la crónica y a la opinión y no tanto a la reflexión o la investigación, esferas, éstas, propias de un discurso teórico más profesional, articulado por contenidos y argumentaciones de mayor rigor conceptual.

Así como fueron escasas las voces teóricas, también fueron precarias las fuentes de divulgación a nivel de revistas especializadas. En el período que comprende este estudio son pocas las revistas nacionales de estudios o investigaciones estéticos asociadas a espacios académicos o centros de investigación. Algunas de ellas fueron la Revista de Artes de la Universidad de Chile, la revista Pro Arte y, en un plano más misceláneo, la revista Atenea de la Universidad de Concepción, y la revista Zig-Zag, entre otras.

Por otra parte, encontramos también otros textos, construidos bajo formalidades y metodologías más rigurosas, que apuestan por una lectura de escenario y que intentan establecer ciertas articulaciones conceptuales más complejas. En este sentido, el Catálogo Oficial Ilustrado, publicado por Ricardo Richon-Brunet con motivo de la Exposición Internacional de Bellas Artes (1910b), intenta dar cuenta del desenvolvimiento de las artes visuales en el país, organizando conceptos y presencia individuales. En 1921 Miguel Luis Rocuant ${ }^{11}$ publicó en Madrid el ensayo de arte Tierras $y$ cromos: Pin-

\footnotetext{
${ }^{11}$ Miguel Luis Rocuant (1877-1948). En 1902 Rocuant publicó el libro Brumas; en 1905, Poesías; en 1908, Impresiones de la vida militar. En 1918 fundó, junto a Fernando Santiván, la Revista de Artes y Letras. Publicó una serie de trabajos de orientación estética, entre ellos: "Los líricos y los épicos", "Las blancuras sagradas", dedicado a la escultura, y "Los ritmos anunciadores", dedicado
} 
tura chilena ${ }^{12}$. De este autor encontramos también el texto Blancuras sagradas, en donde examina algunas obras escultóricas. Otro texto que apuesta por una conceptualización de la pintura nacional fue el de Luis Álvarez Urquieta ${ }^{13}$, publicado en 1928 bajo el título La pintura en Chile. En este libro-catálogo se establecen periodos y conceptos tales como precursores, maestros y movimientos, que encontramos todavía vigentes en textos de autores posteriores e incluso contemporáneos. Tomás Lago, por su parte, en su trabajo El Museo de Bellas Artes 1880-1930, intenta establecer criterios de ordenación para la colección del Museo. Habla ya de precursores extranjeros, de la Academia de Pintura, distinguiendo algunos maestros nacionales gravitantes.

\section{RICARDO RICHON-BRUNET: LA FRONTERA EXTRAVIADA ${ }^{14}$}

La pluma de este crítico se erigió en las décadas iniciales de la pasada centuria en la voz oficial en un escenario fuertemente mediatizado por el centralismo del Estado, por la mirada de las oligarquías sociales y culturales, y por un poder de opinión y formación estética acaparado por la Escuela de Bellas Artes. Sus comentarios de arte, escritos en revista Selecta, en crónica Conversando sobre Arte, y otros medios, valoran la capacidad de los chilenos, después de haber conquistado su Independencia, de organizar su vida social y cultural tomando como modelo a las naciones europeas, por entender que allí -especialmente en Francia- estaba localizado el epicentro artístico. El comentario a este respecto de Richon-Brunet (Revista Selecta 1912) es elocuente: "Todo hombre tiene dos patrias: la suya y París". En este contexto este crítico confiere a Raimundo Monvoisin el mérito de ser el introductor y fundador del arte de la pintura en Chile, en tanto que a Pedro Lira, la virtud de haberla afianzado y proyectado. Respecto de la escultura, señala a Nicanor Plaza como "el iniciador de la gran escuela escultórica chi-

a la música. Rocuant siguió la carrera diplomática, llegando a desempeñarse como subsecretario de Relaciones Exteriores.

${ }^{12}$ En el texto de 99 páginas se incluyen 7 capítulos. La Luz, Retrato, Desnudo, Paisaje, Marina, Animales, Flores.

${ }^{13}$ Luis Álvarez Urquieta (Limache, 1874 - Santiago, 1945). Coleccionista, artista e historiador. Se integra a la Academia de la Historia de Chile en 1933. Dos años después, la Real Academia de Bellas Artes de San Fernando, con sede en Madrid, lo designa como su Miembro Correspondiente. Parte importante de su colección personal de pintura pasó luego a la colección del Museo Nacional de Bellas Artes de Chile.

${ }^{14}$ Para profundizar en este aspecto, ver Zamorano y Cortés (1998).

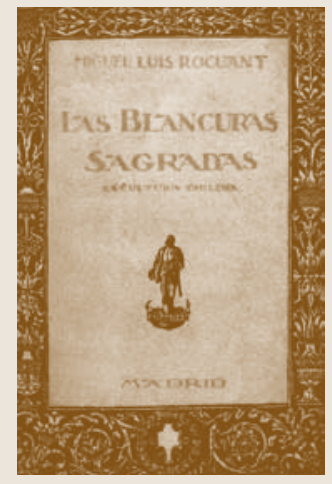


lena: él hizo en la escultura lo que Monvoisin en la pintura: fundar el arte en Chile, y como el pintor también, supo el mismo levantar monumentos hermosos y duraderos sobre estos cimientos echados por él" (Richon-Brunet, 1910a).

El modelo europeo clasicista fue el paradigma que impregnó el escenario de las artes visuales en el país en los inicios de la pasada centuria. Caracterizó la estructura académica de la Escuela de Bellas Artes, los estándares de la crítica, el incipiente mercado artístico local, los criterios de valor para otorgar becas de estudio y las actividades relacionadas con exposiciones y salones de arte. Adherían a este modelo los actores principales de la oficialidad estética nacional, además de aquellos personajes vinculados con la sociedad influyente y el gobierno. Este paradigma, con las mutaciones románticas y realistas que de hecho tuvo, gozará todavía de vigencia hasta mediados del siglo XX, teniendo mayor fidelidad en el concurso social y en ciertos sectores de la crítica conservadora. Su cuestionamiento proviene de algunas voces vinculadas a la literatura, que comienzan a coparticipar de los movimientos vanguardistas internacionales. Junto a ello, en los primeros decenios del siglo XX adquiere mayor gravitación social en el país la clase media y los sectores sociales más postergados, quienes acceden a mayores niveles de educación, incluso al mundo universitario. Un buen ejemplo de ello lo constituye la conformación, en la Escuela de Bellas Artes, de la generación de pintores de 1913, integrada por artistas vinculados a sectores sociales medios e incluso bajos, y a sectores campesinos.

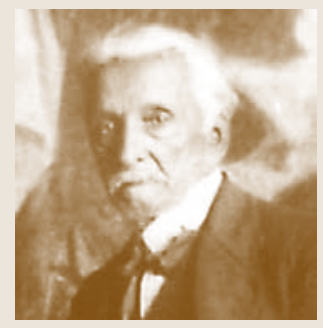

J. F. González

\section{LA CRÍTICA DE ARTE Y LOS PROCESOS VANGUARDISTAS LOCALES}

La crítica de arte se diversificó con el aporte de literatos e intelectuales. Desde la revista del grupo Los Diez (1916-17), la revista Juventud (1911-12 y 1918-21) y la revista Claridad (1920-25) comienzan a objetarse las normas académicas, a la vez que a valorarse las tendencias emergentes. El antagonismo, que se produce entre conservadores y vanguardistas, tiene por protagonistas, de una parte, a aquellos artistas identificados con el Consejo y la Escuela de Bellas Artes y con la crítica más conservadora; y, de otra, a los artistas más jóvenes, liderados por Juan Francisco González. Estos se agrupan en la Sociedad Nacional de Bellas Artes, creada en 1918, entidad cuyo signo contestatario la transforma en alternativa de los esquemas académicos predominantes. El cuestionamiento al modelo clásico y la aparición del 
fenómeno vanguardista tiene una cierta correspondencia con los procesos políticos y sociales que se dan en el país. Una de las figuras que tuvo un impacto potente en estos procesos de innovación estética en Chile fue el poeta Vicente Huidobro (1893-1948). Su vinculación con los movimientos vanguardistas europeos y el conocimiento directo que tuvo de algunos de sus protagonistas, tales como Guillaume Apollinaire, Jean Cocteau, André Bretón, Pablo Picasso y Juan Gris, entre otros, generan una vinculación entre la vanguardia internacional y los procesos estéticos locales. El Non serviam (1914), del vate creacionista, dio sentido y contenido a la innovación en el espacio estético local.

Otro antecedente que ilustra acerca del debilitamiento de la hegemonía del modelo clásico proviene de la visión innovadora del grupo Los Diez ${ }^{15}$, quienes, desde sus distintas disciplinas y sensibilidades, cuestionan al modelo imperante, a la vez que manifiestan claros afanes de renovación artística. Se trata de una alianza espontánea de poetas, pintores, músicos y arquitectos. Donde mejor se definen Los Diez es en la "Somera iniciación al Jelsé", manifiesto escrito por Pedro Prado en 1916. Los Diez representan una organización peculiar, de naturaleza contestataria, que no profesa adhesión disciplinar, ni propuesta estética definida. Su credo consiste en dignificar un concepto de libertad y de ruptura con lo establecido. En cierto modo se representa en nuestro país similares posturas a las planteadas por los intelectuales dadaístas en Europa, más o menos por esta misma época. El grupo Los Diez no establece un estilo corporativo; cada cual cultivó su arte conforme a su propio criterio y visión.

En este escenario, varios artistas comienzan a sumar su voz teórica al debate artístico. Muchos fueron los pintores y escultores que incursionaron en el ámbito teórico ${ }^{16}$. Las dos figuras que marcaron con más fuerza el escenario estético local en los inicios del siglo XX, a los cuales cabe la denominación de figuras patriarcales, fueron Pedro Lira y Juan Francisco González, quienes, además de su obra pictórica, destacan por sus escritos e iniciativas artísticas institucionales. Juan Francisco González (1853-1933) ${ }^{17}$

${ }^{15}$ A pesar de su nombre, los integrantes de este grupo no fueron necesariamente diez. El núcleo fundamental está constituido por Pedro Prado, Manuel Magallanes Moure, Juan Francisco González, Armando Donoso, Julio Bertrand Vidal, Eduardo Barrios, Alberto García Guerrero, Alberto Ried, Acario Cotapos, Ernesto Guzmán, Augusto D’Halmar y Alfonso Leng.

${ }^{16}$ Durante el siglo XIX el pintor Pedro Lira y los escultores José Miguel Blanco, Virginio Arias y Arturo Blanco tuvieron un fuerte protagonismo en el terreno teórico.

${ }^{17}$ Juan Francisco González dictó conferencias, escribió en la prensa con el pseudónimo de "Araucano" y se mezcló en crudas polémicas con los defensores del arte académico.

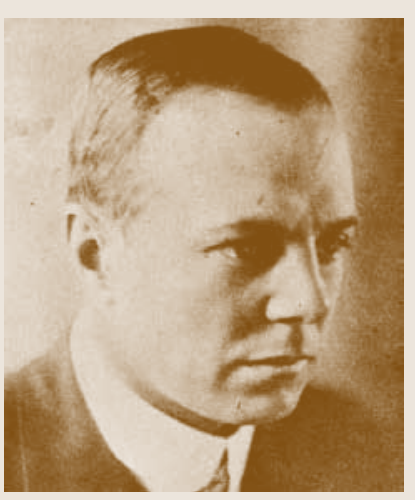

P. Prado 


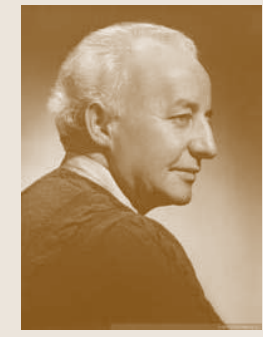

C. Mori

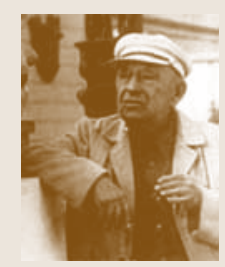

S. Román

fue un pintor antiacadémico, cuya propuesta innovadora le hacía rechazar de plano los preceptos tradicionales y el detallismo fotográfico. Estas concepciones innovadoras arraigan fuertemente en los pintores del Grupo Montparnasse. Otros artistas involucrados en el debate teórico fueron Camilo Mori, Jorge Letelier, Waldo Vila y Samuel Román. En general, la incursión teórica de estos artistas, limitada en cantidad y rigor conceptual, no está articulada por doctrinas o ideas estéticas. Se trata de una escritura impresionista, que nace de una demanda de información y que se posiciona con cierta jerarquía en nuestro medio, durante las primeras décadas del siglo XX, dada la ausencia manifiesta de teóricos del arte.

\section{LA MIRADA INNOVADORA DE JEAN EMAR}

Álvaro Yáñez Bianchi, que escribió con el pseudónimo de Jean Emar ${ }^{18}$, había conocido en París a varias figuras que lideraban la vanguardia europea. En la capital francesa tuvo también contacto con varios pintores chilenos que por esa época residían allí y que luego integran el Grupo Montparnasse. De regreso a Chile, en febrero de 1923, Emar se transformó en crítico de arte y entusiasta promotor de los pintores asociados a este grupo. Desde el diario La Nación, empresa periodística de su padre, Eliodoro Yáñez, comenzó su trabajo de divulgación a través de artículos que hablaron por primera vez en el país sobre distintos temas del arte moderno. Los nombres de Cézanne, de Vlaminck, Van Dogen, entre muchos otros, a los que habría que sumar los de los artistas chilenos vinculados al Montparnasse, son glosados ampliamente en los artículos, crónicas y notas de arte que escribió en La Nación entre los años 1923 y 1927. En cierto modo, Jean Emar dio sustento teórico a un nuevo marco ideológico estético que hacía su estreno en el país, con la presencia de los artistas montparnasseanos. Dedica crónicas a cada uno de sus integrantes, en donde ilustra sobre los fundamentos de este nuevo lenguaje estético. Intenta en esos escritos dar cuenta de la evolución personal y artística de ellos, a la vez que relevar la importancia de su formación en París. Su pluma abre un espacio en el medio local para

${ }^{18}$ Jean Emar es el pseudónimo de Álvaro Yáñez Bianchi (1893-1964). Novelista, crítico de arte, pintor y viajero. Sus principales obras literarias fueron: Miltín (novela, 1934), Ayer (novela, 1934), Un año (novela corta, 1934), Diez (cuentos, 1937), entre otras. Se ha explicado que Jean Emar viene de "J en ai marre", lo que significa en argot francés "estoy hasta la coronilla". Emar había llegado a la capital francesa en 1919, trabajando en la Embajada de Chile como Primer Secretario. Viaja por Europa y asiste a la Academia de La Grande Chaumiére. 
conocer y entender la pintura moderna. Ilustra a la cultura nacional sobre las concepciones de vanguardia y acerca de los debates sobre la estética contemporánea.

Los escritos de Emar ahondaron, sin dudas, los debates ideológico-estéticos en el país. Los conflictos y desavenencias también se dieron, y con fuerza, al interior de la Escuela de Bellas Artes. En este contexto se da la excéntrica intervención del gobierno del general Carlos Ibáñez del Campo, quien cierra la Escuela en $1929^{19}$, enviando a veintiséis alumnos y profesores a estudiar a Europa. Esta medida debe ser entendida como la reacción de un Estado conservador, orientador e interventor, que no entendía ni respaldaba esta estética de quiebre.

\section{ANTONIO ROMERA: UNA VOZ FUNDACIONAL ${ }^{20}$}

En términos generales, el panorama descrito fue el que conoció el español Antonio Romera ${ }^{21}$ cuando llegó a Chile, a fines de 1939, y sobre este medio ejerció su influencia. Romera desarrolla en Chile una vasta labor en el campo de la teoría y la historia de la pintura. Además de sus libros y catálogos, una parte muy relevante de su obra está constituida por sus artículos de prensa, publicados en el diario El Mercurio y otros medios de información, que en su conjunto cubren casi cuarenta años de reflexión y análisis estéticos. En Chile este autor ha sido considerado como un pionero en el estudio de la pintura nacional. Antes de su libro Historia de la pintura chilena, publicado por Editorial del Pacífico en 1951, existían sólo algunas monografías y artículos dispersos publicados en periódicos y revistas. Romera marca el escenario de la crítica de arte en Chile por casi cuarenta años, desde su llegada al país y hasta su muerte, en 1975. Su obra literaria y su pensamiento crítico son un referente obligado a la hora de

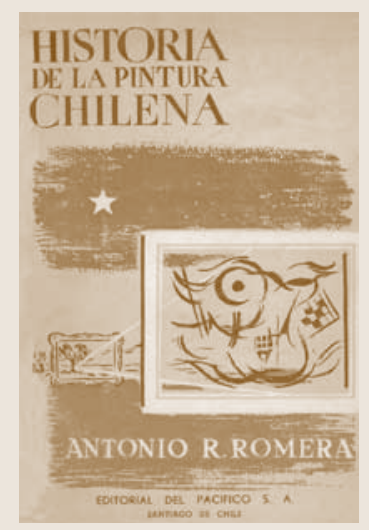

${ }^{19}$ Decreto Supremo del 31 de diciembre de 1929.

${ }^{20}$ Para profundizar en el discurso teórico de Romera, ver Zamorano et al. (2007), pp. 98-117. También Romera (1967), p. 199.

${ }^{21}$ En España Romera había tenido una formación inicial en pedagogía, ejerciendo desde muy joven la docencia. Entre los años 1935 y 1939, en plena época de la Guerra Civil española, es enviado por el Ministerio de Relaciones Exteriores (Junta de Relaciones Culturales del Ministerio de Relaciones Exteriores) a ejercer su profesión a la localidad francesa de Lyon, en donde, además, complementa sus estudios de pedagogía y de estética. En 1937 había contraído matrimonio con Adela Laliga, quien le acompañará hasta su muerte. Estando en Chile, entre 1949 y 1952, fue profesor en el Windson School, al mismo tiempo que crítico de artes visuales, dramáticas y de cine, en distintos periódicos capitalinos. Entre 1942 y 1967 ejerció el oficio de caricaturista en Las Últimas Noticias y, también, en El Mercurio. 

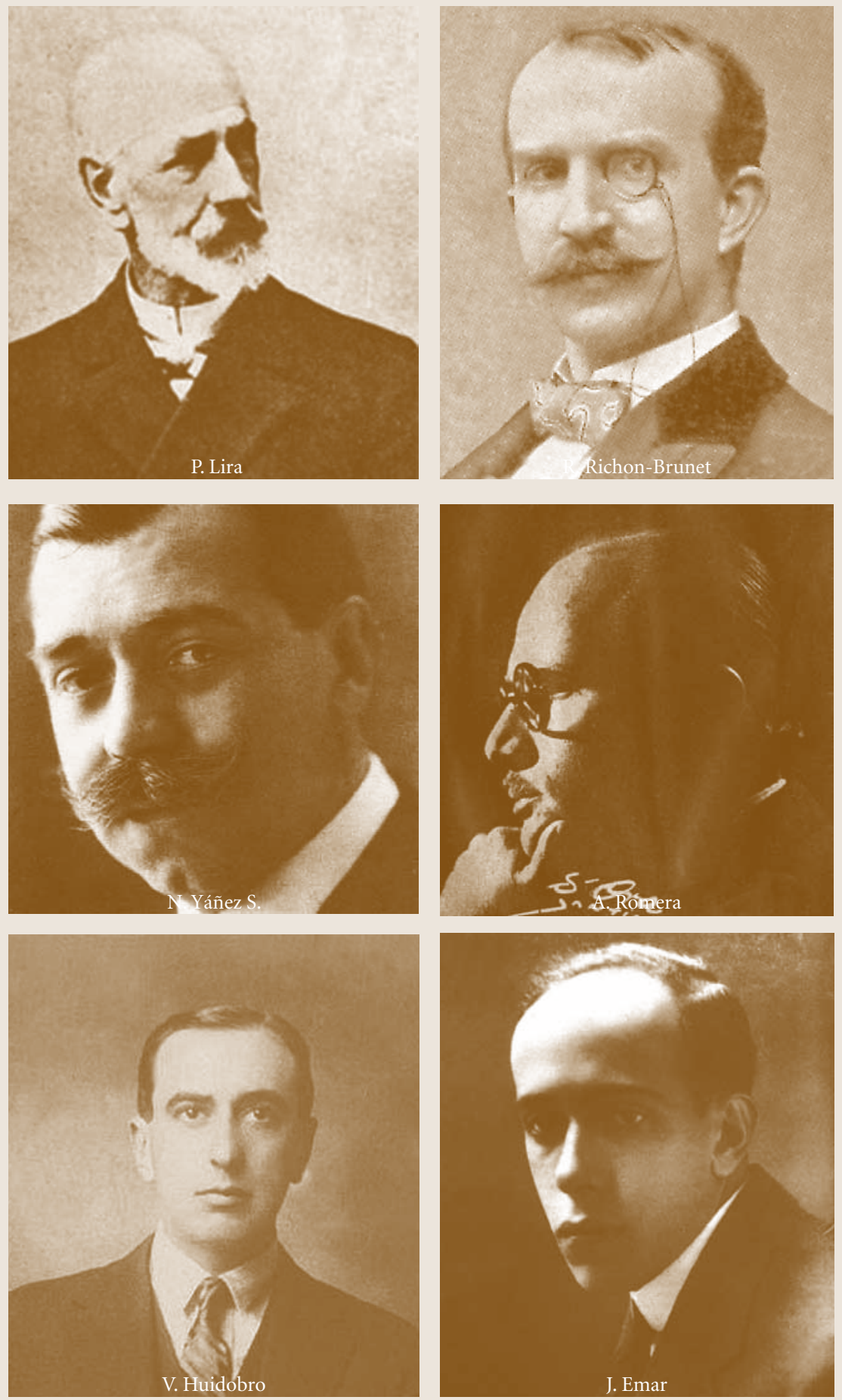

\begin{tabular}{l|l} 
Atenea 504 & 202 \\
\hline II Sem. 2011 & 202
\end{tabular} 
analizar el desenvolvimiento estético-plástico chileno. Los escasos estudios o escritos de arte que se habían publicado a fines del siglo XIX y comienzos del XX revistieron algunas de las siguientes connotaciones: fueron concebidos principalmente como crónica artístico-periodística, género interesante pero carente de rigurosidad conceptual ${ }^{22}$; fueron unilaterales y herméticos en sus posiciones estéticas, especialmente a la hora de legitimar los dogmas académicos; $y$, en general, fueron realizados por personas que no poseían una formación sistemática en aspectos relativos a la teoría o la historia del arte. Al respecto Milan Ivelic señala lo siguiente: "Nuestra tradición crítica no se ha caracterizado, precisamente, por el rigor conceptual y por la amplitud de criterios para ponderar y valorar el fenómeno artístico. Nombres como Richon-Brunet, Nathanael Yáñez o Goldschmidt, ilustran muy bien una etapa de la crítica de arte francamente insuficiente" (Ivelic y Galaz, 1988). A decir de Waldemar Sommer, Romera es una especie de "organizador teórico" (Sommer, 1987) en el desenvolvimiento de la pintura chilena. "Supo situarse respecto a la polémica figuración - no figuración y calibró con mesura y ponderación las nuevas tendencias gracias al estudio que hizo de ellas" (Ivelic y Galaz, 1988). Romera estableció un modelo de análisis para la pintura nacional. Éste consideró una doble mirada. Por una parte, determinó claves y constantes ${ }^{23}$ (Romera, 1976), es decir, propone una forma de organización conceptual, que intenta definir el carácter de nuestra plástica a partir de sus orientaciones y caracteres específicos; por otra, plantea una estructuración de desarrollo cronológico, cuyo mérito fue haber establecido un orden, una estructura diacrónica que jerarquizaba presencias individuales y grupos ${ }^{24}$. Su modelo de análisis no se inscribe en corrientes, ni en escuelas estéticas determinadas. Es un ecléctico, que valora las distintas propuestas estéticas, atendiendo su especificidad formal y su contexto

${ }^{22}$ En muchos casos, cuando se habla de un pintor, las referencias críticas apuntan más bien a cuestiones de entorno y no a la obra misma, o a su proceso creativo. Consideraciones tales como el abolengo del artista, su amplia cultura de origen europeo, su gusto refinado, etc., son muy frecuentes en los textos de Ricardo Richón-Brunet y Nathanael Yáñez Silva, quienes intentan sustantivar el mérito estético de la obra en razón de tales argumentaciones.

${ }^{23}$ Romera habla de las Claves y las Constantes de la pintura chilena. Dentro de las primeras distingue la Exaltación, la Realidad, el Sentimiento, y la Razón Plástica; dentro de las segundas, el Paisaje, el Color, el Influjo Francés, y el Carácter. Estas categorías fueron definidas por primera vez en el estudio Asedio a la pintura chilena, Santiago, Editorial Nascimento, 1969.

${ }^{24}$ Romera definió doce conceptos en torno a los cuales articula el desarrollo de nuestra plástica: los Precursores, el Romanticismo, la Academia de Pintura, Tres maestros solitarios, Los cuatro maestros y sus seguidores, la Generación de 1913, Persistencia del Naturalismo, los Independientes, Grupo Montparnasse, Seguidores y movimientos, Generación del 40, Nuevas tendencias y últimos nombres.

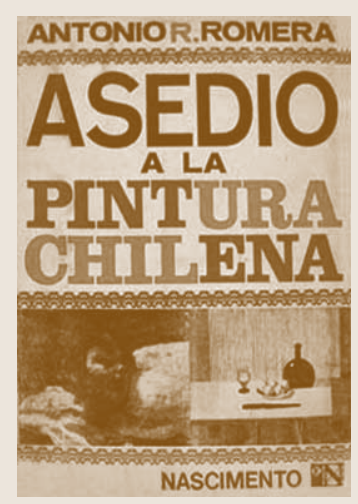

$203 \quad$ Atenea 504 
histórico. La particularidad radica en que mira al arte nacional bajo los parámetros del arte europeo, haciendo permanentes extrapolaciones entre nuestra plástica y las escuelas del Viejo Mundo: la francesa, la española y la italiana, principalmente. Tal situación no resulta extraña en un país como Chile, permeado fuertemente en sus manifestaciones culturales por modelos foráneos. Romera desarrolla y profesionaliza una actividad, cuyo nivel anterior era insuficiente. Ello, tanto por la escasez de críticos cuanto por el bajo nivel de su preparación teórica. De hecho, la posibilidad de realizar estudios de estética, de teoría o crítica de arte en el país es tema reciente. Las universidades nacionales comienzan recién a formar teóricos a partir de los años sesenta ${ }^{25}$. Estimamos que la obra más importante de este autor, por su extensión y profundidad, fue aquélla desarrollada a través de sus artículos de prensa, publicados en los diarios Las Últimas Noticias (donde escribe hacia 1940 con el seudónimo de Federico Disraeli), La Nación (1940 a 1952) y El Mercurio (desde 1952 a 1975), medio de información, este último, especialmente relevante por marcar una fuerte línea de opinión estética en nuestro país.

\section{ALGUNAS EXPOSICIONES EMBLEMÁTICAS ${ }^{26}$}

Algunas exposiciones de arte han tenido en nuestro país una importancia especial y, en algunos casos, hasta una cierta capacidad de articulación del escenario estético local. Unas lo fueron por su significación protocolar, en tanto que otras por su alto impacto mediático o por los niveles de polémica o nuevos conceptos y miradas que lograron instalar. En este sentido, la primera muestra que destaca, en los inicios del siglo XX, fue la Exposición Internacional de Bellas Artes de 1910, conocida como del Centenario ${ }^{27}$. En esta actividad es posible colegir un par de consideraciones; en primer lugar,

${ }^{25}$ De hecho la formación profesional de teóricos comienza en forma bastante tardía. La Universidad Católica desarrolla algunos cursos de estética a partir de la década del cincuenta. Crea el Centro de Investigaciones Estéticas en 1966; el Departamento de Estética en 1968 y el Instituto de Estética, dependiente de la Facultad de Filosofía, el año 1971. Desde 1975 imparte la carrera de Licenciatura en Estética. La Universidad de Chile crea el Departamento de Teoría e Historia del Arte el año 1969, egresando las primeras promociones en 1975.

${ }^{26}$ Aun cuando los Salones Oficiales de Arte cobraron en Chile gran importancia desde el siglo XIX, su análisis e impacto merece ser abordado en toda su extensión en otro trabajo.

${ }^{27}$ La exposición se inauguró el 21 de septiembre de 1910 en el nuevo edificio del Museo y la Escuela de Bellas Artes, en el Parque Forestal. Con tal motivo se constituyeron comisiones organizadoras en los principales países de Europa y América. 
la importancia diplomática que tuvo por el hecho de solemnizar los actos conmemorativos de la celebración secular. Una segunda cuestión tiene que ver con la envergadura de la exposición y el impacto que produjo sobre la escena artística local. Recordemos que, aparte de los salones oficiales, escasas eran las exposiciones de arte que se efectuaban en el país en los inicios del siglo. La Exposición del Centenario, que sirvió también para inaugurar el nuevo edificio del Museo Nacional y la Escuela de Bellas Artes, reunió obras de artistas de más de quince países, principalmente europeos ${ }^{28}$. La muestra fue administrada por el Consejo de Bellas Artes, entidad que era integrada por artistas e intelectuales influyentes del medio local. El catálogo oficial estuvo a cargo del crítico Ricardo Richon-Brunet (1910b). Detrás de la iniciativa estaba el Gobierno, siendo figuras relevantes en la organización el pintor español Fernando Álvarez de Sotomayor ${ }^{29}$, director de la Escuela de Bellas Artes en esa época, y el diplomático Alberto Mackenna Subercaseaux, a quien se designó, además, como comisario general de la Exposición. La gran cantidad de obras extranjeras exhibidas en la muestra, además de los artistas que en ella figuraban, fue vista por algunos como una forma de traer el mundo del arte a nuestro país. La sola representación española -estimulada por la presencia en Chile de Fernando Álvarez de Sotomayor- consideró envíos de casi cuarenta de los mejores artistas peninsulares de la época, muchos de ellos ex becarios Roma y estrechamente vinculados a la Real Academia de Bellas Artes de San Fernando ${ }^{30}$. El comentario de Nathanael Yáñez Silva es elocuente respecto de la percepción que se tuvo en nuestro medio sobre la exposición: "Jamás en Chile había habido una fiesta de arte como aquella. Se refrescaba el espíritu entrando

\footnotetext{
${ }^{28}$ Las bases generales fueron establecidas por el gobierno de Chile mediante Decreto 3786, estableciendo cuatro secciones para la Exposición: a) Internacional, b) Nacional, c) Arte Retrospectivo Nacional, y d) Arte aplicado a la Industria. Todo esto, en lo que dice relación con pintura, escultura, grabado y arte aplicado a la industria.

${ }^{29}$ Fernando Álvarez de Sotomayor (1875-1960) fue contratado en 1908 para servir docencia en la Escuela de Bellas Artes, en la cátedra de Colorido, Dibujo y Composición. En 1910 fue nombrado director de la entidad. Sobre su regreso a España la mayor parte de las fuentes señalan que fue en 1915, sin embargo otras apuntan que su partida fue en 1913. Entre estas últimas apuntamos los datos aportados por Yáñez Silva, Nathanael en La Segunda, Charlas de los sábados, "La época de Álvarez de Sotomayor", 2 de junio de 1945.

${ }^{30}$ Llegaron obras de Fernando Álvarez de Sotomayor, Manuel Benedito, Aureliano Beruete, Ramón Casas, Eduardo Chicharro, Francisco Llorens, Santiago Rusiñol, Joaquín Sorolla, José Villegas, entre otros. La nómina de escultores hispanos estuvo integrada por Mariano Benlliure, con siete piezas de bronce, Miguel Blay y Fábrega, con tres (dos en piedra y una en bronce), Juan Clará, con tres obras, José Clará (seis obras, tres en mármol y tres en bronce), Julio Antonio (dos obras), Antonio Marinas García (una obra), Luciano Oslé (tres obras), Miguel Oslé (cuatro obras) y Enrique Marín Hidalgo, con una obra.
} 


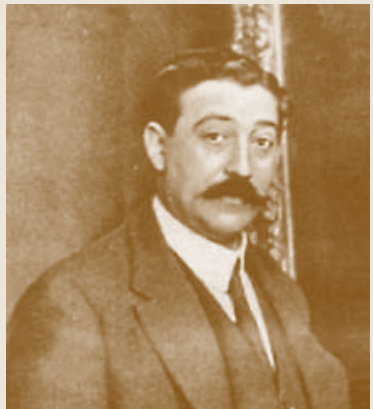

F. Alvarez S. en esas salas, se sentía uno muy bien, como si visitase Europa, porque Europa había venido a nosotros, con su mejor producción y su mejor cariño por esta tierra” (Yáñez Silva, 1955). Esta opinión releva también una valoración al modelo académico europeo que evidenciaba la mayor parte de las obras expuestas. Un modelo todavía vigente en los espacios oficiales del Viejo Continente, como la Real Academia de Bellas Artes de San Fernando y la propia École de Beaux Arts de París, en donde no hacían todavía su entrada las voces vanguardistas. Los delegados chilenos que actuaron en Europa, entre los que se cuenta a Alberto Mackenna Subercaseaux, se habían entendido directamente con las tradicionales academias oficiales, entidades que tenían aún cierta hegemonía sobre el espacio cultural en el Viejo Continente. Recordemos que, en los inicios del siglo XX, España y Francia tenían academias de Bellas Artes en Roma; el Premio Roma era todavía considerado por muchos como la más alta distinción. Este hecho explica que no hayan sido invitados a la Exposición aquellos artistas vinculados a la vanguardia europea, que circulaban por lo general en la periferia de la oficialidad cultural.

En la Exposición del Centenario estuvieron también presentes varios artistas chilenos que habían sido alumnos en la Escuela del pintor español Álvarez de Sotomayor. Algunos de ellos participan años más tarde, en 1913, en una exposición realizada en los salones del diario El Mercurio, en donde adquiere presencia y connotación en la historiografía artística local una generación de pintores que será luego conocida como del Trece o del Centenario. Esta muestra inicial estuvo integrada por el artista español José Prida Solares y los pintores chilenos Pedro Luna y Ulises Vázquez ${ }^{31}$. Se trata del primer grupo generacional que aparece en el arte chileno, unido por circunstancias sociales e intereses estéticos coincidentes. Su obra marca un acento más popular y costumbrista respecto de la pintura que se había hecho en Chile en el siglo XIX. A esto debemos agregar alguna inspiración de raíz hispana, sugerida por el maestro Álvarez de Sotomayor. Los artistas de esta generación manifiestan cierta homogeneidad y sintonía como grupo. En primer lugar, la mayoría procede de niveles sociales medios y bajos, situación que en ocasiones vehicula su pintura hacia un espacio de crítica y enjuiciamiento social. Las pinturas de Gordon, Lobos y Plaza, a modo de ejemplo, plantean una mirada cuestionadora y una vindicación visible

${ }^{31}$ Junto a estos artistas, integran luego al grupo los pintores Agustín Abarca, Enrique Bertrix, Abelardo Bustamante, Jerónimo Costa, Jorge Letelier, los hermanos Alberto, Enrique y Alfredo Lobos Aránguiz, Arturo Gordon, Guillermo Vergara, Elmina Moissan, entre varios otros. 
sobre temas sociales. En el plano estético, estos artistas son principalmente figurativos y su paleta está más cercana de la gama de los colores fríos. Desarrollaron una obra renovada en temas y en concepciones estéticas, que colisionó con los esquemas académicos decimonónicos que imperaban todavía en el corazón de la Escuela. Se trata de una obra muy ajena a los preceptos formales e icónicos en los cuales se había fundado, en la medianía del siglo XIX, la Academia de Pintura. Por esta razón la obra de estos pintores no fue, en su momento, apreciada y reconocida por la oficialidad cultural, por la crítica y por el poder comprador.

Sobre estos artistas se ha ido tejiendo un paradigma, que releva más las difíciles circunstancias de vida de los integrantes del grupo, que el mérito propiamente estético de su obra. "Vivieron -anota Waldo Vila- apresuradamente, como destruyéndose a sí mismos, en una carrera violenta, llena de brillo, pero que duró escasamente algunos años" (Meltcherts, 1963). Pablo Neruda se refirió a ellos como una "Heroica capitanía de pintores" (Neruda, 1966). Independiente de la lectura contemporánea que se haga de la obra de estos autores, su pintura tiene el mérito de acuñar un registro distinto y renovador respecto de los modelos que habían imperado en Chile durante el siglo XIX.

Algunos críticos e historiadores se refieren a la obra y presencia de estos artistas como un paréntesis de hispanidad en la pintura chilena; lapso de tiempo que comienza en 1908, con la llegada al país del pintor Álvarez de Sotomayor, y termina con la irrupción del grupo Montparnasse. A decir de José María Palacios: "Fernando Álvarez de Sotomayor venía a crear un paréntesis en el proceso pictórico chileno. Dicho paréntesis tendrá, por un lado, un carácter neutralizador de la influencia francesa y, por otro, vendrá a provocar un cambio de actitud frente a las motivaciones, mostrando a la vez un cambio significativo en el trato del color" (Palacios, 1983). Dimensionar cuán ancha y profunda fue esta adhesión local respecto de la pintura española es un tema que se hace necesario elucidar. Cierto acento "goyesco" en la obra de Gordon (a quien se llegó a denominar como el "Goya chileno"), la fuerte presencia del retrato y una evidente inclinación hacia la gama de los fríos, pueden definir espacios de coincidencia que, por cierto, resultan insuficientes para apostar por un sello o una inclinación. Quizá sean las nostalgias y los protocolos del Centenario los que propiciaron una mirada de mayor empatía con la "Madre Patria". Este sentimiento de hispanidad fue recogido también por algunas plumas locales, tales como la de Domingo Gómez Rojas, cuando comenta el viaje a España del pintor Alfredo Lobos (Zamorano, 1994, p. 188).

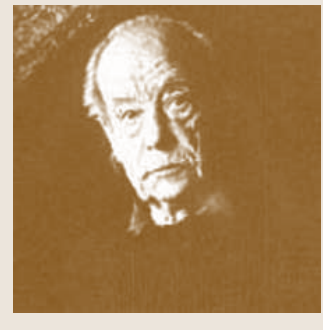

W. Vila 
Renovados aires franceses llegan al país con otra exposición emblemática. Se trata de una muestra realizada en el mes de junio de 1923, en la Casa de Remates "Rivas y Calvo" de Santiago, por los pintores del Grupo Montparnasse ${ }^{32}$. Estos artistas habían tenido contacto con el ambiente parisino y con algunas figuras de la vanguardia europea de ese entonces. "Montparnasse, barrio de artistas en París, en cuyos cafés, academias y exposiciones, bulle gran parte del porvenir de las artes plásticas y donde muchos 'ídolos caducos' se han destrozado, muchas ideas rancias sepultado y no pocas semillas, que luego germinaron, han sido sembradas" (Emar, 1923). Reintegrados en el país y liderados por el pintor Luis Vargas Rosas se unen para levantar un testimonio de disconformidad en contra del predominio academicista que todavía imperaba en el país.

La exposición de 1923 produjo asperezas y convulsionó al público y a la crítica oficial, que adhería todavía a los relictos academicistas. Nathanael Yánez Silva, una voz ciertamente conservadora, señaló acerca de la muestra: "No creemos que en esta exposición se realice innovación alguna" (Yáñez, 1923).

La muestra pretendió exaltar los lenguajes artísticos y los autores más cercanos a las vanguardias, soslayando los relictos académicos (naturalismos, romanticismos, realismos, etc.) que todavía gozaban en el país de gran aceptación. La posición revolucionaria de los montparnassianos produjo más reacciones que adeptos, pero entre los que miraron con buenos ojos esta propuesta se encontraba el maestro Juan Francisco González. El código del Grupo Montparnasse -estimulado por la reflexión teórica de Jean Emar- mira con simpatía los preceptos teóricos de Paul Cézanne, el racionalismo cubista y el desborde cromático de los fauves. Sumemos a todo esto la gran acentuación proyectiva de los sentimientos dados por el Expresionismo alemán, recogidos por algunos integrantes del grupo. En junio de 1925 este grupo vuelve a exhibir en la sala "Rivas y Calvo". La muestra "Salón de Junio" fue apoyada por el diario La Nación y la llamaron "Exposición de Arte Libre". Se exhibieron también obras "extranjeras" al concurrir con piezas de Picasso, Gris y Lipchitz, entre otros.

\footnotetext{
${ }^{32}$ En junio de 1923, en la Casa de Remates “Rivas y Calvo” de Santiago, se presenta la primera exposición de estos artistas que se habían formado en París. Integran este grupo, entre otros, Luis Vargas Rosas (1897-1977), Enriqueta Petit (1900-1984), Julio Ortiz de Zárate (1885-1946), Manuel Ortiz de Zárate (1887-1946), Augusto Eguiluz (1893-1969), José Perotti (1898-1956), Jorge Letelier (1887-1963), Hernán Gazmuri (1901-1979), Camilo Mori (1896-1973) e Isaías Cabezón (1891-1936).
} 
Otra muestra que tuvo un gran impacto en la escena artística local fue la Exposición de Pintura Francesa Contemporánea, conocida con el nombre "De Manet hasta nuestros días", realizada en el Museo Nacional de Bellas Artes, en mayo de $1950^{33}$. El catálogo oficial de la muestra cuenta con textos del entonces conservador del Museo del Louvre, René Huyghe, y de Gastón Diehl, comisario general de la Exposición. Los textos de ambos teóricos, que reflexionan sobre la escena pictórica francesa de fines del siglo XIX y primera mitad del XX, en cierto modo, reeditan en nuestro país, a partir de obras originales, un debate abierto en Chile, 25 años antes, por los artistas montparnassianos y la pluma de Jean Emar. Huyghe comenta lo siguiente:

Mas, si el 'Fauvismo' abría una brecha en la Realidad todavía en pie, si el cubismo empleaba sin escrúpulos sus ruinas derribadas, los Surrealistas traían como secuela la anarquía tras haber introducido la revolución: en medio de esas ruinas dispersas, entre esa 'membra disjecta', hicieron saltar su dinamita e imaginaron profanaciones vengativas y refinadas. En sus lienzos asistimos a los vagidos de una génesis todavía incierta o la disolución última de la creación (Huyghe, 1950).

La exposición, que se realiza nada más trascurridos cinco años de finalizada la Segunda Guerra Mundial -"1940-1944, ese ancho vacío, esa pesadilla poblada de gritos guturales y de soldados con botas" (Huyghe, 1950)-, además de ser un acontecimiento estético de la máxima jerarquía, puede ser entendido también como un acto de vindicación diplomática; una manera en que Francia se sobreponía a un momento dramático de su historia, mostrando al mundo una parte muy significativa de lo mejor de su producción pictórica. La muestra incluyó 137 obras originales de distintos artistas: impresionistas, simbolistas, fauvistas, cubistas, surrealistas, hasta las generaciones más jóvenes. El público y los artistas locales pudieron ver obras de Edouard Manet, Claude Monet, Berthe Morisot, Camille Pizarro, Augusto Renoir, Henri de Tolouse-Lautrec, Pierre Bonnard, Maurice Denis, George Braque, André Derain, Roaul Dufi, Fernand Leger, André Lhote, Albert Marquet, Henry Matisse, Pablo Picasso, Georges Roault, Jacques Villón, además de los artistas jóvenes más promisorios de la Escuela Francesa.

${ }^{33}$ La muestra se realizó con los auspicios del Ministerio de Educación Pública de Chile y a iniciativa del Comité France-Amerique, por el Instituto de Extensión de Artes Plásticas de la Universidad de Chile. 
La exposición fue atacada por algunas voces conservadoras, entre ellas $\mathrm{Na}-$ thanael Yáñez Silva y Miguel Venegas Cifuentes. Yáñez Silva hizo el siguiente comentario: "Al pintor ya formado esta exposición le servirá de estudio. Pero para el joven pintor que está empezando, todo aquello va a ser contraproducente, le va a esgrimir, no lo va a lanzar a la cara. Cosa peligrosísima, como elija de proyectil el cuadro Coutaud (n. 89) 'Los siete fierros'... ¿ Hay en el conjunto un gran cuadro, una gran emoción artística? Fuera de Monet y Sisley, no la sentimos" (Yáñez, 1950).

La muestra, sin embargo, tuvo un impacto significativo en las generaciones más jóvenes de artistas y estudiantes de arte. A decir de José Balmes, tuvo la capacidad de modificar la mirada de los que entonces eran estudiantes de arte; al respecto comentó: "Para nosotros fue muy importante. Recuerdo que durante más de un mes de exposición pasamos todos los días en el museo. Porque en ese momento encontramos que ahí estaba la respuesta a la modernidad; nos decíamos que así como ellos hablan de sus propios problemas, nosotros teníamos que hablar con ese lenguaje pero de nuestros problemas" (Badal, 1950).

En 1968 se realizó en la Quinta Normal de Agricultura, en el antiguo edificio del Museo de Arte Contemporáneo, la célebre Exposición "De Cézanne a Miró". La muestra, cuya importancia radica sobre todo en su capacidad de movilización de opinión pública, fue visitada por miles de personas.

Mario Carreño en El Mercurio de Santiago, diario que auspició la exhibición que se realizó entre el 21 de junio y 17 de julio de ese año, señaló lo siguiente: "Uno de los aspectos más fascinantes de este arte en esta excelente exposición que se inauguró en el Museo de Arte Contemporáneo, es que los maestros escogidos, más que pintores, en su mayoría son inventores" (Carreño, 1968). Fue una exposición que hizo historia en nuestro país, tanto por la singularidad de las obras expuestas como por su efecto mediático.

\section{REFERENCIAS}

Badal, Gonzalo (Ed.) (1995). “Los años de formación 1939-1959”, Balmes. Viaje a la pintura. Santiago de Chile: Ocho Libro Editores, 50.

Emar, Jean (1923, 22 octubre) "Grupo Montparnasse", diario La Nación, p. 3.

Carreño, Mario (1968, 22 de junio). "De Cézanne a Miró. Los inventores nuevos", diario El Mercurio, p. 10.

Diario El Mercurio (1950, 8 de mayo). “Nathanael Yáñez Silva”, p. 77. 
El Diario Ilustrado No 7842 (1923, jueves 25 de octubre). "Nathanael Yáñez Silva”, p. 4.

Emar, Juan (1925, 11 de junio). "Alrededor del Salón de Junio", en diario $\mathrm{La}$ Nación, p. 7.

Huyghe, René (1950). "La joven pintura francesa y sus maestros”, Catálogo de Exposición “De Manet hasta nuestros días". Santiago de Chile: Museo Nacional de Bellas Artes.

Ivelic, Milan y Galaz, Gaspar (1988). Chile: arte actual. Valparaíso, Chile: Ediciones Universidad Católica de Valparaíso.

Letelier, Rosario; Morales, Emilio y Muñoz, Ernesto (1993). Anales de Artes Plásticas de la Universidad de Chile. Santiago de Chile: Editorial Universitaria.

Lira, Pedro (1902). Diccionario biográfico de pintores. Santiago de Chile: Imprenta Encuadernación y Litografías Esmeralda.

Lago, Tomás (1930). El Museo de Bellas Artes 1880-1930. Santiago de Chile: Editorial Universidad de Chile, Departamento de Extensión Cultural y Artística.

Lizama, Patricio (2003). Jean Emar, Notas de Arte. Santiago, Chile: Centro de Investigación Barros Arana, Dirección de Bibliotecas, Archivos y Museos.

Meltcherts, Enrique (1963). "Relaciones entre la pintura chilena y española". Goya N $\mathrm{N}^{\circ}$ 5, julio-agosto, p. 65.

Neruda, Pablo (1966). "Una capitanía de pintores" (prólogo), en Vila, Waldo, Una capitanía de pintores. Santiago, Chile: Editorial del Pacífico.

Palacios, José María (1983). Catálogo exposición del artista Arturo Gordon. Santiago, Chile: Instituto Cultural de Las Condes.

Revista Selecta, 5 (1912, agosto). "Richon Brunet”, p. 141.

Richon-Brunet, Ricardo (1910a). Catálogo Oficial Ilustrado, Exposición Internacional de Bellas Artes. Santiago de Chile: Imprenta Barcelona.

Richon-Brunet, Ricardo (1910b, abril). Crónica Conversando sobre Arte, "Un recuerdo de La Araucana - El Caupolicán” de Don Nicanor Plaza. Selecta $\mathrm{N}^{\circ} 1$, p. 9.

Romera, Antonio (1969). Asedio a la pintura chilena. Santiago de Chile: Editorial Nascimento.

(1967). “Experiencias de un crítico de Artes Plásticas”. Aisthesis No 2, La crítica de arte y sus problemas en Chile (Pontificia Universidad Católica de Chile, Santiago de Chile), p. 199. Bello.

Sommer, Waldemar (1987). "Panorama de la pintura chilena desde los precursores hasta Montparnasse”, en catálogo de exposición del Instituto Cultural de Las Condes.

Yáñez Silva, Nathanael (1923, 25 de octubre). Exposición del grupo Montparnasse" (Sala Rivas y Calvo). Diario Ilustrado, p. 4. 
(1950, 8 de mayo). El Mercurio, p. 77.

(1955). “Grandes exposiciones de arte", en Número Especial de Revista

Zig-Zag, Medio Siglo de Zig-Zag 1905 a 1955, Santiago de Chile, impreso en los talleres de la revista, p. 222.

Zamorano Pérez, Pedro (1994). El pintor F. Álvarez de Sotomayor y su huella en América. La Coruña, España: Ediciones Universidad de La Coruña.

Zamorano Pérez, Pedro y Cortés, Claudio (1998). "Pintura chilena a comienzos de siglo: hacia un esbozo de pensamiento crítico". Aisthesis $\mathrm{N}^{\circ} 31,89$ 107.

Zamorano Pérez, Pedro, Cortés, Claudio y Muñoz, Patricio (2007). “Antonio Romera; asedios a su obra crítica”. Aisthesis $\mathrm{N}^{\circ} 42,98-117$. 